\title{
LOS QUE MURIERON EN LA FORTALEZA DEL REAL FELIPE (1825-1826)
}

Those who died in the Real Felipe fortress (1825-1826)

\author{
Manuel Zanutelli Rosas ${ }^{1}$
}

\section{Resumen}

Después de la batalla de Ayacucho, el general español Rodil se negó A ACEPTAR LA RENDICIÓN ESPAÑOLA Y SE PARAPETÓ EN LA FORTALEZA DEL REAL. Felipe en el Callao. Junto a la guarnición realista se refugiaron LAS FAMILIAS NOBLES TODO AQUEL IDENTIFICADO CON LA MONARQUÍA ESPAÑOLA. LA FORTALEZA FUE SITIADA POR LAS TROPAS INDEPENDENTISTAS. EL SITIO ACARREÓ MUCHAS MUERTES ENTRE LOS SITIADOS, BIEN SEA POR LAS ESCARAMUZAS, LAS ENFERMEDADES Y EL HAMBRE. RODIL SE RINDIÓ DESPUÉS DE 9 MESES Y 17 DÍAS DE SITIO.

Palabras claves: Rodil, independencia, Real Felipe, Callao, sitio.

\section{Abstract}

After the battle of Ayacucho, the Spanish general Rodil refused to ACCEPT THE SPANISH SURRENDER AND BARRICADED IN THE FORTRESS OF REAL Felipe in Callao. Along with royal troop, the noble families and EVERYONE IDENTIFIED WITH THE SPANISH MONARCHY SOUGHT REFUGE. THE FORTRESS WAS BESIEGED BY PRO-INDEPENDENCE TROOPS. . THE SIEGE BROUGHT MANY DEATHS AMONG THE BESIEGED, EITHER BY SKIRMISHES, DISEASE AND HUNGER. RODIL SURRENDERED AFTER 9 MONTHS AND 17 DAYS OF SIEGE.

Key words: Rodil, independence, Real Felipe, Callao, siege.

\section{LA METAMORFOSIS DE LOS OPORTUNISTAS}

a proclamación de la Independencia el sábado 28 de julio de 1821 fue un acto político de gran trascendencia, un contundente testimonio de rechazo al gobierno español en el Perú. Al retirarse de Lima rumbo a la sierra, el teniente general José de La Serna dejó como encargado de la ciudad a don Pedro José de Zárate y Navia, marqués de Montemira,

Periodista y escritor de crónicas.

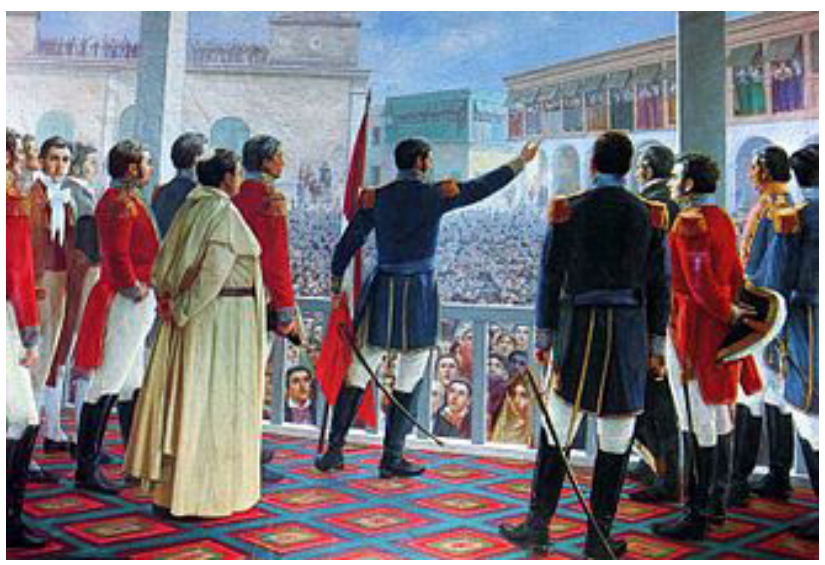

quien "sacó de palacio la bandera peruana al lado de San Martín".(1)

Se levantaron tabladillos para repetir la escena en la Plaza de La Merced; en la Plaza de Santa Ana, próxima a la iglesia de las Descalzas; y, en la de la Inquisición, "mirando" al antiguo Tribunal del Santo Oficio.

Como en todo proceso de esta naturaleza, se produjo una vergonzosa metamorfosis política. Quienes habían vivado a los virreyes se trasformaron en fervientes republicanos; cambiaron de piel como las serpientes, sin ningún rubor, sin ningún bochorno. Es

1 Mendiburu, Manuel de: Diccionario histórico biográfico del Perú, tomo VIII, pág. 369. Lima, 1890. Imprenta de Torres Aguirre. 
pertinente entonces recordar la pregunta que se formuló Luis Alayza y Paz Soldán en su estudio Unanue, San Martín y Bolivar, en el sentido que no podía "establecerse cuánto hubo de honroso en su tardia adhesión a la patria y cuánto de arribismo". (2)

No vacilaron en acercarse al municipio a firmar el acta histórica los condes de San Isidro, de la Vega del Ren, de Casa Saavedra, de San Carlos, de Torre Antigua, de Orué, de las Lagunas, de Torreblanca, de Vistaflorida, de San Juan de Lurigancho; y, los marqueses de Villafuerte, de Casa Dávila, de Montealegre, de San Juan Nepomuceno, de Torre Tagle, de Corpac y de Torrehermosa. Igual conducta tuvieron los condes de Cartago, de Castañeda, de Polentinos, de San Javier y de Torre Velarde. Hubo criollos que senegaron a firmar, como José de Irigoyen, Francisco Moreno, los miembros de la Audiencia de Lima, los marqueses de Casa Calderón, Castel Bravo de Rivero y de Castellón. (3) Al menos, ellos se mantuvieron firmes en su postura intransigente, al margen del oportunismo canalla.

Rubricaron ese documento, con los merecimientos de su trayectoria de vida en bien de la patria, Toribio Rodríguez de Mendoza, y el sacerdote Javier de Luna Pizarro, Tomás Méndez Lachica, Tomás Ortiz de Zevallos, Justo Figuerola, Miguel Tafur, Pedro Tramarria, José Manuel Dávalos, Mariano José de Arce, Francisco Moreyra Matute, el sacerdote Francisco Javier Mariátegui, Manuel García de la Plata y Urbaneja, Juan Francisco de Izcue, Guillermo del Río y José Guillermo Geraldino, entre otros.

2 Lima, 1934, pág. 174.

3 Anna Timoty, E.: La caída del gobierno español en el Perú. El dilema de la Independencia. Lima, 2003; Instituto de Estudios Peruanos.

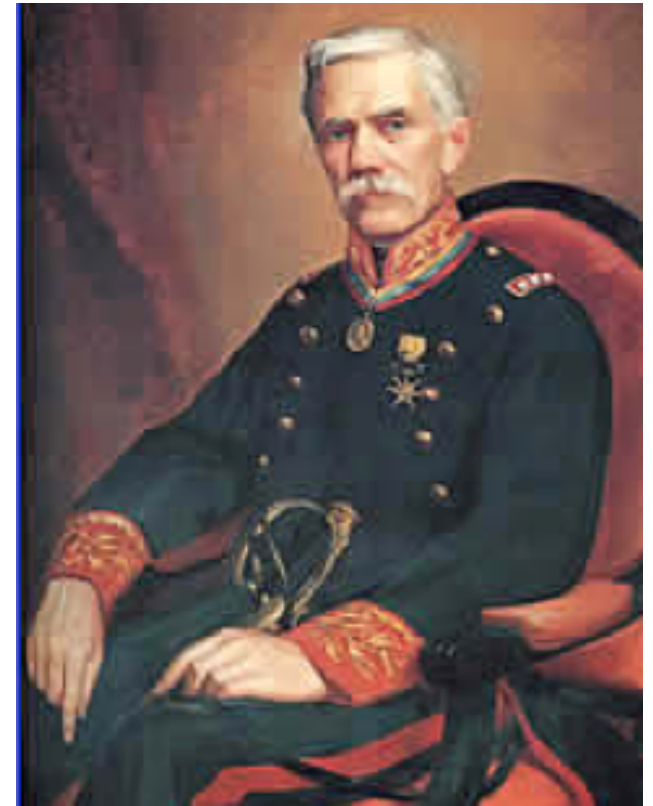

BARTOLOMÉ SALOM, JEFE SITIADOR DEL REAL FELIPE.

\section{El Real Felipe}

Último jefe político y militar del Callao, José Ramón Rodil estuvo en el Perú desde 1816 y asumió el mando de la fortaleza en reemplazo del teniente coronel José María Casariego el $1^{\circ}$ de marzo de 1824 . Se negó tercamente a reconocer la Capitulación de Ayacucho, suscrita por el virrey La Serna el 9 de diciembre del citado año. Y, desde el 2 de abril de 1825 los miembros de la sociedad limeña que no se resignaban a la fundación de la República, buscaron refugio en ese reducto al amparo del brigadier español, quien no reconoció La cláusula 11 de la Capitulación, que señalaba: 11. La plaza del Callao será entregada al ejército unido libertador, y su guarnición será comprendida en los artículos de este tratado.

- Concedido; pero la plaza del Callao, con todos sus enseres y existencias, será entregada a disposición de S.E. el Libertador dentro de veinte días.

Los refugiados temían la violenta reacción de 


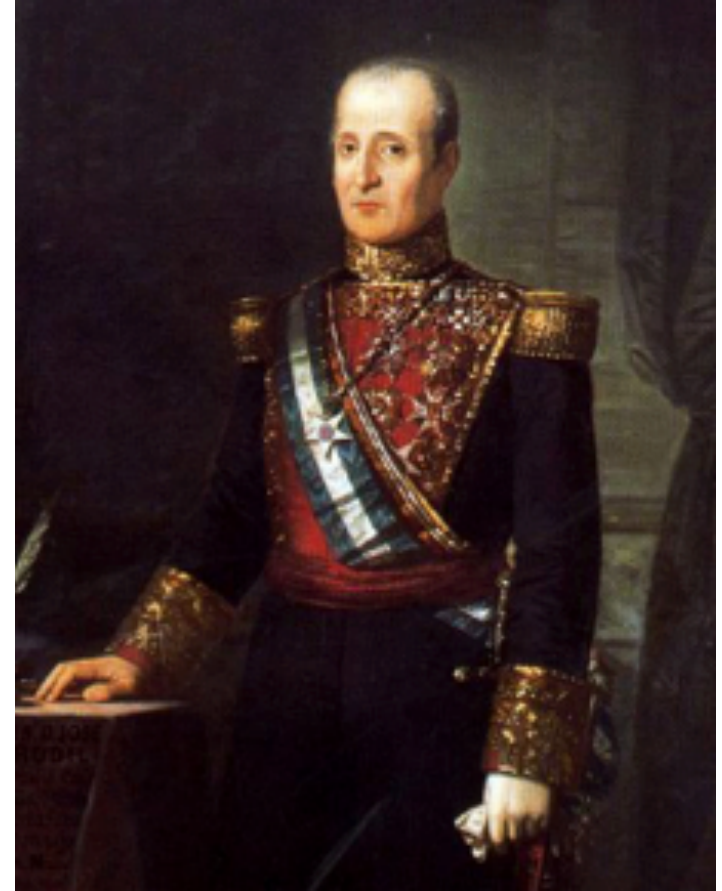

José Ramón Rodil y CAMPILlo

Simón Bolívar. Siempre estuvieron con Dios y con el Diablo, y en ese vergonzoso vaivén disfrutaron del poder. Aplaudieron a los virreyes y después rindieron pleitesía a los generales de Junín y Ayacucho.

\section{Tras LaS MURALLAS}

La falta de víveres ocasionó serios problemas de subsistencia. En los primeros meses a los refugiados les alcanzaban "un pan grande, dos onzas de arroz, una onza de carne salada y un poco de harina, cebada o maíz". (4) Pero las provisiones se fueron acabando y Rodil ordenó disminuir las raciones. Se requerían cítricos para evitar el escorbuto que al presentarse fue motivo de alarma por sus fatales consecuencias. Algunos notaron que se les inflamaban los ojos y se producían sangrados en las encías.

4 "Actuados del proceso Berindoaga" reproducidos por M. F: Paz Soldán, en Historia del Perú independiente. En Unanue, San Martín y Bolívar, de Luis Alayza y Paz Soldán, Lima, 1934, pág.435.

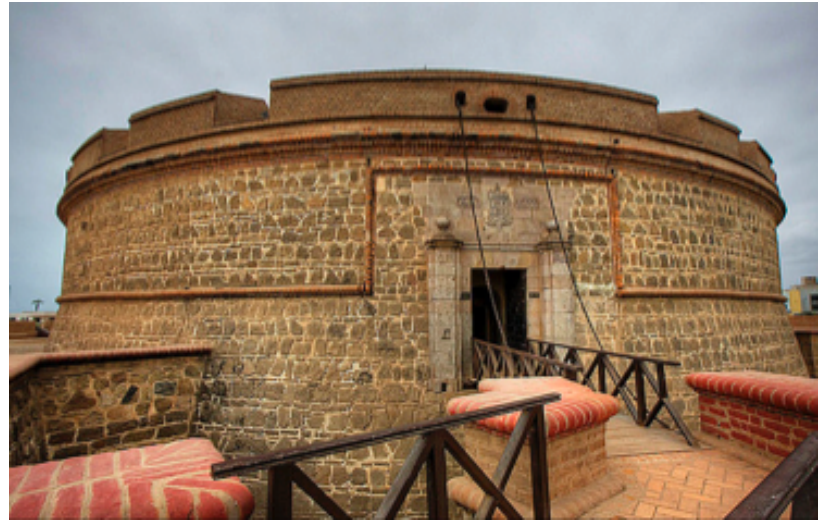

Fortaleza del Real Felipe, Callao

Rodil anota en sus memorias: "me están atormentando las enfermedades de escorbuto, vicho o disentería e hidropesía, peculiares de navegaciones y sitios largos y obran en la guarnición como epidemia mortífera".

Con el transcurso del tiempo resolvió desprenderse de las "bocas inútiles" (personas que solo consumían) y de los enfermos; de esa manera reservó víveres y medicamentos para la guarnición.

"Yo, que necesitaba minorar la población para suspender consumos que no podian reponerse, mandé que los que no pudieran subsistir con su provisiones o industrias salieran del Callao. Esta orden fue cumplida con prudencia, con pausa y con buen éxito". ${ }^{(5)}$

Los heridos debieron haber sido trasladados a Lima para su internamiento en el Hospital de San Andrés; pero, Rodil solo admitió este acto humanitario en las últimas semanas de su encierro. El nosocomio estaba próximo a la plazuela de Santa Ana.

El ejército de la patria podía renovar las bajas,

5 En El Callao Histórico, de Eleazar López Contreras. Caracas, 1926, pág. 136. 
darle descanso a su tropa e incrementar el armamento. En cambio, Rodil carecía de estas ventajas.

\section{JOYAS POR HUEVOS}

Las joyas se depreciaron al extremo de no valer más allá de lo que costaban uno, dos o tres huevos; la carne era un lujo que muy pocos podían permitirse. En el juicio incoado a Juan de Berindoaga y Palomares, vizconde de San Donás, declaró ser de Lima, de 41 años, católico, apostólico y romano. Dijo, por ejemplo, que la alimentación de los sitiados siempre fue insuficiente desde las primeras semanas. La carne de caballo se vendía a seis reales la onza.

Sobre el encierro, el horror y la desesperanza el general Manuel de Mendiburu trazó estas líneas:

La situación del Callao por momentos se hacía más critica e inminente. Los sitiadores la estrechan, y la escasez de subsistencias pronto llegó a presentar el aspecto del hambre mortifero. Alli se consumieron caballos, mulas, asnos, gatos, perros y hasta ratones siendo ya casi imposible para las familias acomodadas hallar algunos viveres que iban agotándose y que pagaron a precios fabulosos.

Crecieron estas miserias amenazadoras con el desarrollo del escorbuto y otras temibles enfermedades mientras que Rodil ostentando el más frío y artificioso denuedo, daba espantosas muestras de su indolencia e inhumanidad que se aumentaban conforme progresaba el infortunio, la agonía y desesperación decuantos en aquel encierro tenian la existencia a merced de la ferocidad de un individuo. ${ }^{(6)}$

6 Diccionario histórico-biográfico del Perú, tomo séptimo, 1887, pág. 125.

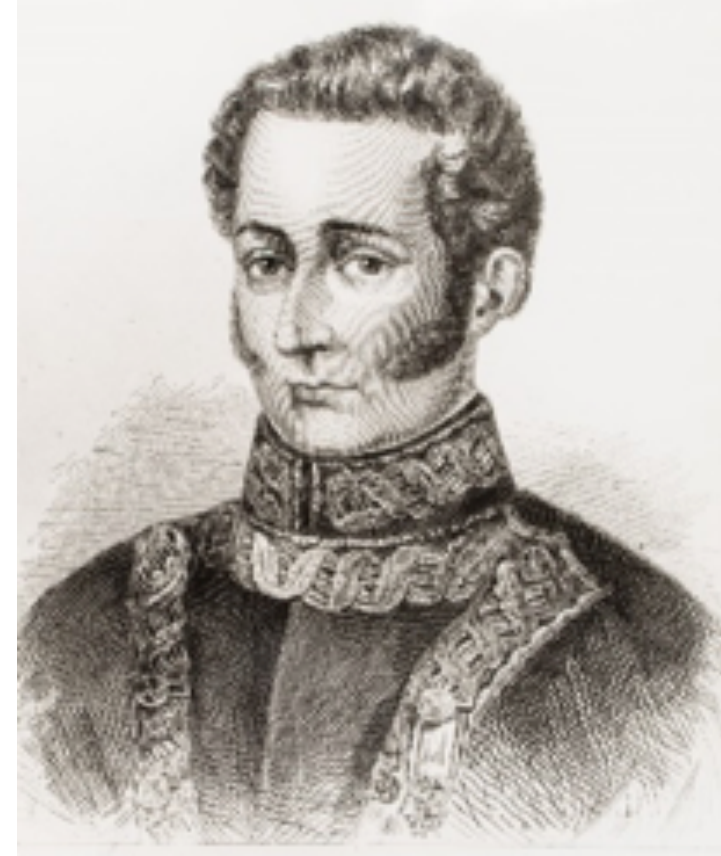

El MARQués De TorRe TAgLE

Agregó algo muy importante $\mathrm{y}$, en cierta manera, esclarecedor:

Nosotros creemos que en el Callao se encerraron cerca de 7,000 [soldados] habiendo salido con vida a lo sumo 2,300; el resto quedó sepultado en aquel vasto cementerio. Con respecto a los ajusticiados, tenemos por evidente que fueron cerca de 200.

Hasta las raciones de carne de caballo, principal fuente de alimentación, se habían reducido. En este caso apenas quedaban cincuenta ejemplares y hubo que reducir las raciones de comida. ${ }^{(7)}$

\section{El MarQués de Torre Tagle}

José Bernardo de Tagle y Portocarrero nació el 21 de marzo de 1779, en el hogar de José Manuel Tagle e Isásaga y Josefa Portocarrero y Zamudio, "descendiente del conde de la

7 López Contreras, Eleazar: Obra citada, 136. 
Monclova". ${ }^{(8)}$ Se casó el 6 de junio de 1800 con Juana Rosa García de la Plata y Orbaneja, hija del oidor Manuel García de la Plata y de Benita Orbaneja y Lallemand. Se instalaron "en su soberbia mansión de la calle de San Pedro, con gran lujo y esplendor" pero falleció de tuberculosis en 1811 a los 30 años de edad. ${ }^{(9)}$ La pareja tuvo tres hijos; le sobrevivió una niña "con la razón trastornada".(10)

El marqués contrajo un segundo matrimonio con Mariana Micaela Echevarría y Santiago de Ulloa en la parroquia del Sagrario el 20 de julio de 1819, hija del coronel Juan de Echevarría y Beingoechea y de Ana María de Santiago y Ulloa García de Lara. Los casó el presbítero Matías Maestro y fueron testigos Mariana Ulloa y Samuel Senra. Pero, existe otra partida, con fecha del 19 de diciembre de 1819; y, fueron testigos Juan y Josefa Echevarría y Tiburcio de la Hermosa. Era "una hermosa viuda" hija de los marqueses de Iranda; se había casado el 29 de diciembre de 1807 con Demetrio O Higgins, gobernador político y militar de la provincia de Huamanga e intendente de la Real Hacienda. ${ }^{(11)}$

Amigos y parientes solían visitarlo; y, a todos agasajaba con largueza. Una sirvienta le contó a Elena Ortiz de Zevallos, nieta del marqués, que "doña Mariana cuando entró a manejar su casa, cesó el despilfarro... A costa del señor marqués venían a comer todos los ociosos y a quitarles la plata". Y agregó: "el señor marqués se miraba en su mujer, y era tan hermosa que cuando salía en la calesa la gente se agolpaba para verla". ${ }^{(12)}$

De su matrimonio con Maríana Echevarría (o

8 Mendiburu: VIII:10.

9 Lavalle, José Antonio de: Galería de retratos de los gobernantes del Perú independiente 1821-1871. Barcelona, 1909, pág. 18.

10 Alayza Paz Soldán: obra citada, pág. 519.

11 Sagrario, Libro 11 de matrimonio, folio 142.

12 Alayza Paz Soldán, Luis. Unanue, San Martín y Bolívar. Lima, 1934, pág. 519.
Echeverría) nacieron: Josefa Manuela Felipa, María Manuela de la Asunción, Mariana Micaela y José Manuel Apolinario.

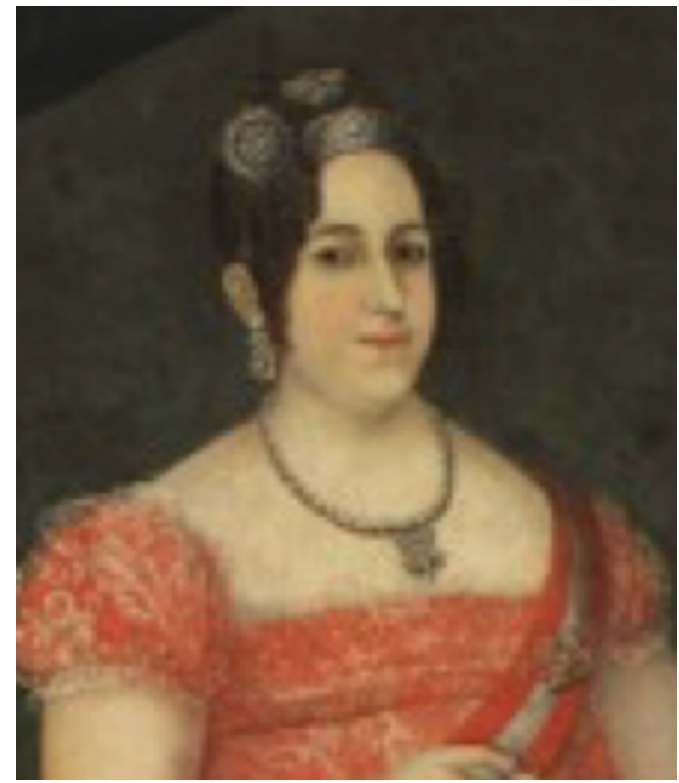

Doña Mariana Micaela de Echevarría Santiago

Luis Alayza Paz Soldán escribió a propósito de Torre Tagle: "parece que vivió constantemente bajo el imperio de la marquesa, mujer de quien la historia nos presenta como de talento y de carácter, y para que resultase más incontrastable su poder, de una belleza maravillosa".(13)

Alcalde de Lima entre 1811 y 1812, Torre Tagle a través del tiempo se desempeñó como diputado a Cortes en España (1813); en Lima el virrey José Joaquín de la Pezuela lo nombró su edecán y en 1820 La Serna le confió la Intendencia de Trujillo. En 1821, la nación lo distinguió con la Orden del Sol en calidad de fundador. Ostentaba el grado de mariscal de campo.

El 3 de marzo de 1824 cometió la descomunal torpeza de firmar un documento donde decía 
estar "convencido de la canalla que constituye la Patria" y, por lo tanto, afirmaba, "he resuelto en mi corazón ser tan español como don Fernando". ${ }^{(14)}$

El 14 de marzo de ese año, en un boletín del ejército, impreso en Huancayo, en una proclama escribió Tagle: "El tirano Bolívar y sus indecentes satélites han querido esclavizar al Perú y hacer este opulento territorio súbdito del de Colombia". Y, en un declarado enfrentamiento afirmó: "Bolivar es el mayor monstruo que ha existido sobre la tierra". ${ }^{15)}$

Los Tagle -el marqués, su esposa doña Mariana y sus hijos-, después de haber estado ocultos en el Monasterio de las Monjas Mercedarias, se dirigieron en caravana al Callao el 27 de febrero de 1825, con todos sus amigos y allegados en la creencia que estarían más seguros en alguna nave extranjera al ancla en la bahía. Al no cumplirse esta invocación solicitaron el apoyo de José Ramón Rodil, quien accedió a darles posada y los instaló en su residencia con todas las comodidades que podía brindarles en ese momento. Era una amplia zona de la fortaleza lejos de las cuadras.

\section{LA TRAGEDIA Y EL HORROR DEL ASEDIO}

Doña Mariana Echevarría dio a luz a Ramón, pero el alumbramiento en esas circunstancias de horror y muerte fue una tragedia. No hubo un médico a su lado, ni siquiera una partera o una simple "recibidora", y por las condiciones en que se había producido el parto falleció atacada de "fiebres malas".

Su partida de defunción fue redactada de la siguiente manera:

14 Lo publicó Alayza y Paz Soldán: 89.

15 Alayza: 259.
En diez y siete de agto. de mil ochoc. veinticinco en esta Parqa. de S. Simón y S. Judas Tadeo de Bellavta., Puerto del Callao: Yo el tnte. de Cura, Relijo. Franciscano di sepulta. con ento. mayor al cadáver de Da. María Ana Echevarría, mujer del Sr. Marqz. de Torre Tagle, como de treinta y ocho años. Murio con todo auxo. y lo firmo. Fr. Bernardo López.

En una nota se expresa. "El día 18 se hicieron las Honrr. a esta finada Echevarría. López". Al margen: "Da. Ma. Ana Echevarría, de Lima. Pagó mand."

Su hermana Mercedes, soltera, natural de Lima, "como de edad de 42 años", había rendido tributo a la muerte, mucho antes, el 10 de junio de 1825; y, según el documento eclesiástico "solo recibió el Sto. Óleo sub. conditione". ${ }^{(16)}$

También finó la madre política del marqués. Todo este drama produjo en Torre Tagle una fuerte depresión. Abrazado a su esposa, decía: “Te seguiré muy pronto". Sabedor de que su fin estaba próximo, se preparó a bienmorir. Su testamento "es fecho" el 20 de setiembre de 1825 , ante el notario José Joaquín Salazar. ${ }^{(17)}$

Hombre de fe, profundamente religioso, "en cama, gravemente enfermo, pero en todo mi acuerdo, memoria y entendimiento natural", confesó su creencia en "el misterio de la Santa Trinidad: Padre, Hijo y Espíritu Santo, tres personas distintas y un solo dios verdadero". Después de estas expresiones, que suponemos fueron como una catarsis antes de enfrentarse a lo desconocido, procedió a dictar su última voluntad. Nombró albacea y tenedora de sus bienes a su suegra; y, en segundo lugar al periodista español Gaspar Rico y Angulo. En

16 Libro, $\mathrm{n}^{\circ} 1$ que empieza en 1793 y termina en 1832, folio 158. 17 Protocolo 672, folios 281-282v. 
condición de albacea-director al abogado Juan de Berindoaga y Palomares.

Días después expira "como a las seis y cuarto de la mañana", sostuvo en el recurso que dirigió al gobernador de la ciudadela la señora Santiago de Ulloa. Alcanzó a recibir los auxilios espirituales del cura de la parroquia de San Simón y San Judas Tadeo. Esperó la muerte con pasmosa serenidad, escuchando himnos religiosos como aquel que decía:

“Viene ya mi dulce encanto/Viene, viene disfrazado/Al descanso duradero/ me acompañe sin temor". ${ }^{(18)}$

"Acostándose en su cama mi abuelo, le puso el cura la Santa Unción en los pies, manos y cabeza. Es tradición en mi familia que mi abuelo se vistió con su uniforme de mariscal, de gran parada, cuando salió con vela encendida en mano a recibir al Santísimo Sacramento de la Eucaristía que llevaba".

Él y su familia fueron sepultados por el presbítero Manuel de Bengoechea en la zona de la Mar Brava, acomodados en simples cajones artesanales, sin pulir, de madera basta, pues no había tiempo para más. A los pies de sus padres puso a Ramón. Al cabo de muchos años, el 27 de abril de 1853, sus restos y los de $\mathrm{su}$ esposa fueron conducidos al Cementerio General de Lima e inhumados en el cuartel Jesús y María, nichos 23 y 24.

Por la información dispersa que se ha trasmitido, todo hace pensar que, además del escorbuto, la tifoidea fue otra de las enfermedades que produjo innumerables bajas, a las que se sumaron los padecimientos de los heridos en combate.

18 Versión de Elena Ortiz de Zevallos y Tagle, nieta del marqués; figura en el anexo $C$ de la obra citada de Alayza.
El historiador Rosendo Melo (1847-1915) hizo este relato:

Torre Tagle y casi toda su familia de cuarenta personas, a excepción de los niños, el conde de Lurigancho, Aliaga [Diego] -vicepresidente en la administración de Torre Tagle- Rico, Izcue, Ex Helmes, Bedoya, Morante, las familias más expectantes del virreinato sucumbieron en la ciudadela. Una gallina llegó a venderse en 25 a 30 pesos y los demás viveres obtenían precios proporcionales. ${ }^{(19)}$

Se contaba con agua pero ni pensar en la higiene diaria o en un simple aseo de las manos. Sobrevivieron los más fuertes, no siempre los señores $y$, menos aún, las damas de la sociedad, todos ellos acostumbrados al confort, a la comida oportuna, a las exquisiteces que les permitía su condición y a la vida muelle, a la blandura de los acostumbrados a no hacer nada.

Desaparecieron también los condes de San Juan de Lurigancho, de Castellón y de Fuente González; la hija del marqués de Valleumbroso doña Petronila Zavala San Lorenzo de Bravo de Rivero; Francisco Moreyra y Matute, esposo de doña Mariana Avella Fuertes y Querejazu; y el hermano de doña Mariana, don Juan, esposo de María del Carmen Tagle.

Otra enfermedad que se presentó en el sitio fue la disentería, que arrasó con un número considerable de soldados. Murió igualmente Manuel Ex Helme, del Tribunal del Consulado y acreditado comerciante de Lima.

En la capital vivían médicos como Félix Devoti, Cayetano Heredia, Miguel Tafur, José Manuel

19 El Callao. Monografía histórico geográfica. El Callao antiguo, tomo segundo. Lima, 1900. Imprenta de Carlos Prince, calle del Correo $\mathrm{N}^{\circ} 48$. 
Valdés y el español Pedro Belomo, entre otros. ¿Por qué no los llamaron?

Personaje de la época y protagonista de los sucesos que recordamos, Guillermo Miller comentó que los sitiados "sufrieron una calentura contagiosa que se propagó y mató varios miles de hombres, consecuencia necesaria de la escasez de provisiones que experimentaban". Y agregó: "muchas familias de las clases más distinguidas adictas a la causa del rey y que voluntariamente se encerraron con Rodil, perecieron en la miseria". La respetable señora $\mathrm{N}$. de Ulloa sobrina del célebre viajero de este nombre, sus dos hijas (una de ellas la marquesa de Torre Tagle), su hijo, y varias nietas preciosas, y, en fin, todos los individuos de aquella numerosa familia murieron durante el sitio. El conde de Lurigancho, el Sr. D. Diego Aliaga, vicepresidente que fue de la república en tiempo de Torre Tagle, Rico, Izcue, Ex Helme, Morote y muchas otras personas de rango y distinción se encontraban entre las víctimas. De otras tres o cuatro familias que componían cerca de 50 personas, solo dos de edad muy tierna sobrevivieron; y de más de cuatro mil infelices que se retiraron".

"Hay diferentes opiniones acerca del número de víctimas de su delirante contumacia. Los escritores lo conjeturan en variadas cifras hasta llegar a 8000 personas: nosotros creemos que en el Callao se encerraron cerca de 7 000, habiendo salido con vida a lo sumo 2300 , el resto quedó sepultado en aquel vasto cementerio. Con respecto a los ajusticiados, tenemos por evidente que fueron cerca de 20. Las conferencias de paz promovidas por el brigadier Rodil para la entrega de la plaza del Callao principiaron el 18 de enero, y terminaron el 22 en que se firmó y ratificó la capitulación". (20)

En la época que estamos tratando, sin anestesia y sin medicamentos adecuados, el sufrimiento de los heridos en combate fue de espanto.

\section{Capitulación}

Rodil firmó la capitulación el 19 de enero de 1826, a las doce del día, y el general Bartolomé Salom la hizo llegar al Consejo de Gobierno. Dejó la fortaleza y marchó con lo que quedaba de su tropa entre una columna de cazadores. Se embarcó a bordo del Briton, nave inglesa al ancla en la bahía del Callao. Derrotado militarmente y vencido en su orgullo reaccionó de manera grosera y vulgar "con los puños crispados", vomitando "un duro apóstrofe a los peruanos, precedido de una interjección". A lo que agregó: "iBrutos los encontré y brutos los dejo!".

20 Manuel de Mendiburu: obra citada: VII, 127. 